\title{
A cross-sectional seroepidemiological study of camel (Camelus dromedarius) brucellosis and associated risk factors in the Sultanate of Oman
}

\author{
Abdulmajeed Hamood Alrawahi ${ }^{1}$, Ian Robertson ${ }^{2}$, Muhammad Hammad Hussain ${ }^{1, *}$ and Muhammad Saqib ${ }^{1,3}$ \\ ${ }^{1}$ Animal Health Research Center, Ministry of Agriculture and Fisheries, Sultanate of Oman \\ ${ }^{2}$ College of Veterinary Medicine, School of Veterinary and Life Sciences, Murdoch University, Perth, Australia \\ ${ }^{3}$ Faculty of Veterinary Science, University of Agriculture, Faisalabad, Pakistan
}

\begin{abstract}
Brucellosis is a globally distributed and economically devastating zoonotic disease of multiple species, including camels. Human and livestock brucellosis is prevalent in Oman, especially in southern Dhofar governorates of Oman, where camels share habitat and have close contact with other susceptible species. We conducted a randomized crosssectional sero-epidemiological study to investigate the seroprevalence of brucellosis in camels of Oman. The sera from 2,250 camels from 552 geographically marked farms were screened through Rose Bengal plate agglutination test and later confirmed by the competitive ELISA (COMPLIZA, VLA, UK). In total, nine [0.4\%, confidence interval (CI) $0.4,0.8$ ] camels from eight $(1.5 \%$, CI $0.6,2.8)$ herds were tested positive for brucellosis. The highest prevalence was recorded in Dhofar $(3.7 \%$, CI 1.4, 7.9) and the lowest in Sharqiyah $(1.3 \%$, CI $0.0,7.2)$ governorate $(p=0.052)$. All seropositive camels were of local breed and females. Seroprevalence was higher $(0.5 \%$, CI $0.2,1.0)$ in adults ( $>4 \mathrm{yr}$ of age) as compared with young $(\leq 4 \mathrm{yr}$ of age) camels $(0.2 \%$, CI $0.0,0.8)$. The results of binary logistic regression indicated that camel herds located in south (Dhofar) [odds ratio (OR) 6.39, CI 1.01, 40.67], practice of open replacement system (OR 14.49, CI 1.83, 114.51) and with history of abortions (OR 8.01, CI 1.34, 47.77) were more likely to test positive for brucellosis. We conclude that brucellosis is endemic at a low level in camels of Oman and a control strategy based upon test-and-slaughter/inclusion of camels in the current vaccination program after carefully planned vaccine evaluation studies could be considered to control it.
\end{abstract}

Keywords: Brucellosis, Camel, Oman, Risk factors, Seroepidemiology.

\section{Introduction}

Brucellosis causes direct and indirect losses to livestock through abortions, premature births, metritis, reduced fertility, and reduced milk yield (Seleem et al., 2010; Gwida et al., 2012). It is regarded as an important re-emerging communicable disease in the Middle Eastern and Mediterranean countries (Brown et al., 2014). Nearly, every case of human brucellosis has an animal origin and, therefore, control is primarily a veterinary concern (Nicoletti, 2002). Although several studies have concluded that the consumption of raw camel milk and camel meat are potential sources for transmission of the bacterium to humans (Omer et al., 2007; Hadush et al., 2013), no specific programs for the control and eradication of the disease in camels have been implemented yet (Sprague et al., 2012).

The disease has been reported frequently in camels, particularly if there has been contact with infected small ruminants (Erdenebaatar et al., 2004; Dawood, 2008). The incidence of the clinical disease is reported to be rare in camels; however, the possible shedding of organisms in milk may lead to disease transmission in humans (Corbel et al., 2006).

Human and livestock brucellosis caused by Brucella melitensis is endemic in Oman and records from the
Ministry of Health and Animal Health Research Center point toward the endemic human and livestock brucellosis in the Southern Dhofar governorate (Ismaily et al., 1988; Idris et al., 1993; Scrimgeour et al., 1999). A retrospective study examining $3 \mathrm{yr}$ of data from the Dhofar Human Hospital revealed that $63 \%$ of cases were due to consumption of raw milk, especially from cattle or camels, and $83 \%$ of patients had a history of contact with live animals (El-Amin et al., 2001). In 1986, a study conducted in Oman found that 3.6\% of sampled camels were seropositive for brucellosis (Ismaily et al., 1988). Subsequent surveys reported variable seroprevalence of $18.2 \%$ (1999), 9.1\% (2000), $7.1 \%$ (2001), and $1.07 \%$ (2002) in studies conducted by Ministry of Agriculture (MAF, 2003). A national brucellosis control program was implemented in 2003 in the endemic region (Dhofar governorate) of Oman. This control strategy included carpet vaccination (Rev. 1) except in camels due to lack of optimal data of safety, potency, and protective efficacy (vaccinationchallenge trial) of Rev. 1 in dromedary (Radwan et al., 1995). Most recently, Rev. 1 has been found safe and immunogenic in lactating and young camels (Benkirane et al., 2014). 
Nonetheless, the vaccine efficacy is yet to be elucidated both in control (vaccination challenge trial) and field trials before it could be considered for a brucellosis control program in camels. Despite all the fright about brucellosis in camels of Oman, before the study reported here, the prevalence of brucellosis in camels in Oman has not been investigated on epidemiological grounds. This study was planned to explore the prevalence of brucellosis in camels of Oman and identify the risk factors.

\section{Materials and Methods}

\section{Study design and sampling}

A cross-sectional serological study was conducted in all the governorates of Oman. The sample size was calculated at an expected prevalence of 50\% (unknown disease prevalence), 95\% confidence levels, and 5\% error margin (Thrusfield, 2007). The required sample size was to include at least 385 herds of camels in the study. This number was further stratified according to the population proportion of camels in each governorate and wilayats (district) of Oman. Inside wilayats, camel herds were randomly selected from different locations. Random selection of the herds and camels was carried by using the Survey Toolbox software (Cameron, 1999). The blood samples were drawn from 2,255 (254 males and 2,001 females) camels originating from 552 randomly selected geographically marked farms/herds (Fig. 1). The sampled camels were further divided into two age groups viz., young (less than equal to $4 \mathrm{yr}$, $n=684$ ), and adults (above $4 \mathrm{yr}, n=1,566$ ) of age. A large proportion of camels belonged to local breeds $(n=2,226)$ followed by imported $(n=18)$ and cross breeds $(n=6)$. Epidemiological data were collected from the sampled farms and animals to build a geodatabase.

\section{Serological diagnosis}

Sera were initially screened through Rose Bengal plate agglutination test (RBT) and later confirmed

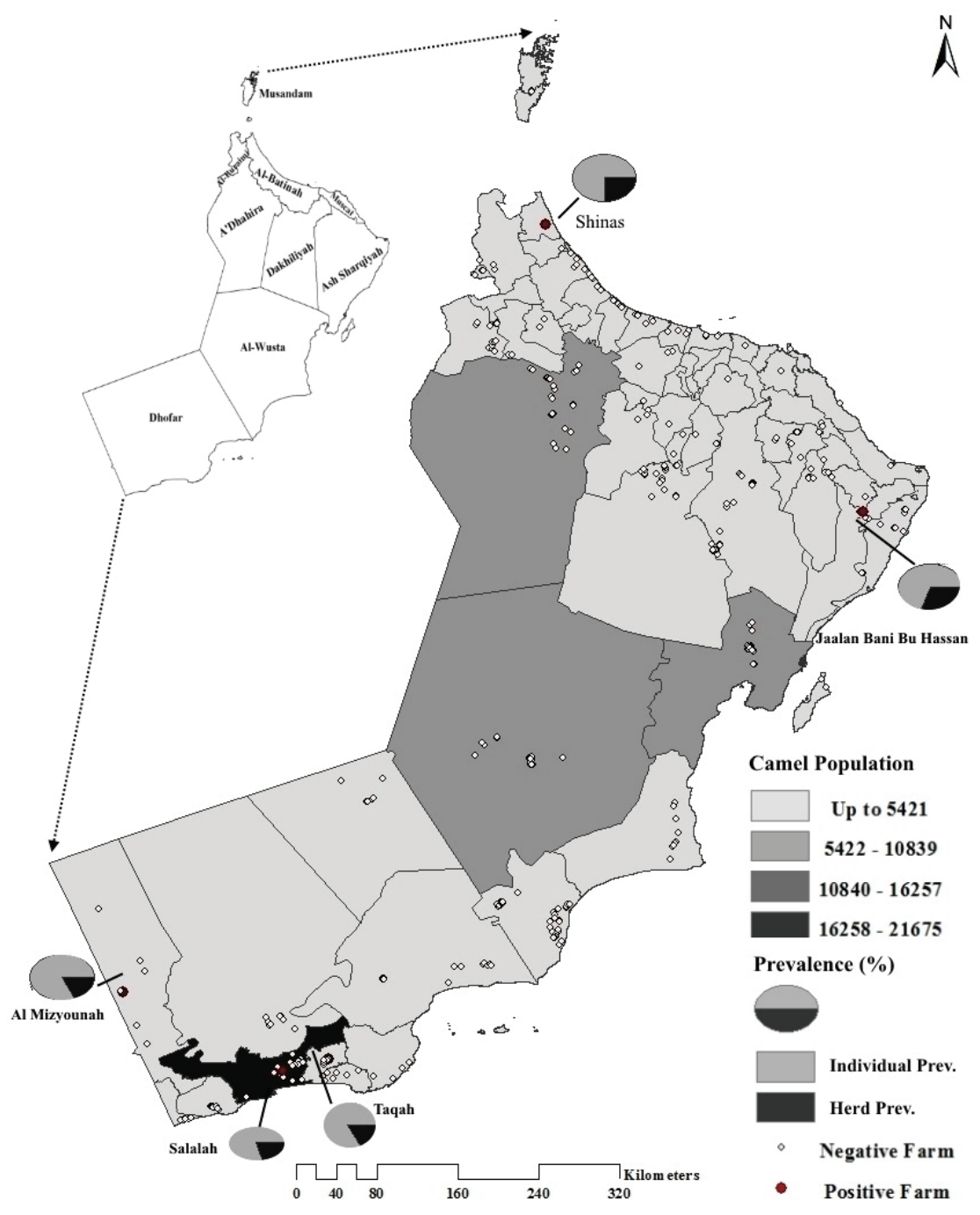

Fig. 1. Distribution of camel population in different wilayats, location of sampled and brucellosis positive camel herds along with herd and individual prevalence in Oman. 
with a commercially available competitive ELISA (COMPELISA-400, VLA, UK) for the presence of anti-burcella antibodies (Perrett et al., 2010). The tests were performed by strictly adhering to the instructions of the manufacturer.

\section{Data analysis}

Prevalence along with 95\% confidence intervals (CIs) was computed. Initially, a univariable analysis was conducted, and odds ratio (OR) along with 95\% CI was calculated for different variables. All variables with $p \leq 0.20$ based on the Wald statistics were used to construct a backward stepwise binary logistic regression model. The fit of the final model was assessed by observing values of the Hosmer-Lemeshow test, the Nagelkerke $R$ square test and the observed versus predicted values (residual statistics), to identify outliers at 0.5 cut off point (Urdaz-Rodríguez et al., 2009). All relevant analyses were performed by using IBM SPSS Statistics 17.0 for Windows $^{\circledR}$ (IBM Corporation, New York, USA).

\section{Results}

In total, 2,255 camels were sampled during this study. However, one of the owners indicated that five of his camels were vaccinated against brucellosis by attending veterinarian recently, along with other ruminants. Therefore, these samples were omitted, and analysis was performed on 2,250 (252 males and 1,998 females) samples. In the initial screening through RBT, 10 samples were found positive. However, when subjected to cELISA, 9 out of the 10 RBT positive samples gave a positive reaction. The overall herd-level seroprevalence was $1.5 \%$ (CI 0.6, 2.8), and the highest prevalence was recorded in Dhofar governorate $(3.7 \%$, CI $1.4,7.9)$ followed by Al Batinah $(2.5 \%$, CI $0.1,13.2)$ and Ash Sharqiyah $(1.3 \%, \mathrm{CI} 0.0,7.2)$ governorates $(p=0.052)$ (Table 1). In the north of Oman, two camel herds were found positive in the wilayats of Shinas (Batinah) and Jaalan Bani Bu Hassan (Al Sharqiyah). In Dhofar (South), six herds were positive for brucellosis in three wilayats (Al Mizyounah, Salalah and Taqah) (Fig. 1).

At animal-level, seroprevalence recorded was $0.4 \%$ (CI 0.2, 0.8), and the highest was recorded in Dhofar $(0.8 \%$, CI $0.3,1.6)$ and Al Batinah $(0.8 \%$, CI 0.0, 4.6) governorates followed by Ash Sharqiyah (0.4, CI 0.0, $2.2), p=0.052$. All seropositive camels were female $(0.45 \%)$ and of local breed $(0.4 \%$, CI $0.2,0.8)$. The prevalence was slightly higher in camels above $4 \mathrm{yr}$ of age $(0.51 \%$, CI $0.2,1.0)$ than those below $4 \mathrm{yr}$ of age $(0.14 \%$, CI $0.0-0.8), p=0.207$. In infected herds, the within-herd prevalence varied from $1.7 \%$ to $20 \%$ $(p=0.386)$. The majority $(62.5 \%, n=5)$ of the positive camels were kept in mixed herds with other ruminants (cattle, goat, and sheep).

The influence of individual-level variables (age, sex, and breed) and herd level variables (herd size, cohorts, housing, management, replacement, history of abortion in a herd, and location) on the seroprevalence of brucellosis in camels are summarized in Table 2. The analysis of individual-level variables indicated that adult camels ( $>4 \mathrm{yr}$ ) were more likely to test positive than young camels ( $\leq 4 \mathrm{yr}$ ) (OR: 3.51 , CI $0.44,28.12)$, $p=0.237$. No analysis was possible for sex, breed, and individual animal abortion history because all positive camels were females of local breeds with no prior history of abortion.

At herd-level, univariable analysis indicated that herds; with more than 15 heads (OR 4.19, CI 0.84, 20.95), where camels were kept only (OR 3.26, CI 0.39, 26.74), managed separately (OR 1.27, CI $0.30,5.36)$, with open replacement system (OR 3.70, CI 0.73, 18.85) and loose housing (OR 5.95, CI 7.27, 48.71) were more likely to

Table 1. Individual and herd-level seroprevalence of brucellosis in camels $(n=2,250)$ randomly sampled from different governorates of Oman.

\begin{tabular}{lcccc}
\hline Governorate & \multicolumn{2}{c}{ Individual } & \multicolumn{2}{c}{ Herds } \\
\cline { 2 - 5 } & $\begin{array}{c}\text { Number positive/ } \\
\text { number tested }\end{array}$ & $\begin{array}{c}\text { Prevalence } \\
\mathbf{9 5 \%} \mathbf{C I})\end{array}$ & $\begin{array}{c}\text { Number positive/ } \\
\text { number tested }\end{array}$ & $\begin{array}{c}\text { Prevalence } \\
\mathbf{( 9 5 \%} \mathbf{C I})\end{array}$ \\
\hline Al Batinah & $1 / 118$ & $0.9(0-4.6)$ & $01 / 40$ & $2.5(0.1-13.2)$ \\
Al Buraimi & $0 / 140$ & $0(0-2.6)$ & $0 / 43$ & $0(0-8.2)$ \\
Al Dakhiliyah & $0 / 138$ & $0(0-2.6)$ & $0 / 41$ & $0(0-5.6)$ \\
A'Dhahira & $0 / 135$ & $0(0.3-2.7)$ & $0 / 40$ & $0(0-8.8)$ \\
\hline Dhofar & $7 / 904$ & $0.8(0-1.6)$ & $6 / 162$ & $3.7(1.4-7.9)$ \\
Musandam & $0 / 6$ & $0(0-45.9)$ & $0 / 2$ & $0(0-84.2)$ \\
Muscat & $0 / 15$ & $0(0-21.8)$ & $0 / 4$ & $0(0-60.2)$ \\
Sharqiyah & $1 / 247$ & $0.4(0-2.2)$ & $1 / 75$ & $1.3(0-7.2)$ \\
Al Wusta & $0 / 547$ & $0(0-0.7)$ & $0 / 145$ & $0(0-2.5)$ \\
Total & $09 / 2250$ & $0.4(0.4-0.8)$ & $8 / 552$ & $1.5(0.6-2.8)$ \\
\hline
\end{tabular}

Individual-level prevalence was not significantly different among various governorates, $F=2.56, P=0.109$. Herd-level prevalence was not significantly different among various governorates, $F=3.79, P=0.052$. 
test positive for brucellosis. However, the association was not significant $(p>0.05)$. Camel herds doweling in southern Dhofar governorate (OR 7.46, CI 1.49, 37.37) and with the history of abortions (OR 8.71, CI 2.12, $35.81)$ were significantly $(p<0.05)$ more likely to test positive for brucellosis (Table 2).

Of the seven variables analyzed through univariable analyses (Table 2), abortion history in herd $(p=0.003)$, herd size $(p=0.081)$, replacement system $(p=0.116)$, housing $(p=0.096)$, and location of herd $(p=0.014)$ were found to be associated with brucellosis (Wald $p \leq 0.2$ ). These variables were used to construct the initial multivariate model (Table 3 ) and the final binary logistic regression model indicated that camel herds located in south (Dhofar) (OR 6.39, CI 1.01, 40.67), practicing open replacement system (OR 14.49, CI $1.83,114.51$ ) and with history of abortions (OR 8.01, CI 1.34, 47.77) were the variables associated with the high prevalence of brucellosis in camel herds of Oman (Table 3$)$. The Hosmer and Lemeshow test $\left(\chi^{2}=1.313\right.$, $p=0.519)$ and Nagelkerke $R$ Square (0.209) indicated that it is a suitable model to predict seroprevalence of brucellosis in camel herds of Oman.

\section{Discussion}

Camels play an important social and economic role for pastoralists in many regions of the world and are a valuable source of milk, meat, transport, leather, and wool as well as beings used for recreational activities (Rollefson, 2000). However, diseases, such as brucellosis, can affect production and productivity (Tibary et al., 2006). RBT is economical, simple, and rapid screening assay performed with a stained Brucella abortus (S99 or S1119-3) suspension at $\mathrm{pH}$ 3.6-3.7 and plain serum. Because of high sensitivity $(>99 \%)$ and the rise of false positive reactions in large ruminants, the present OIE guidelines recommend that all RBT positive results be confirmed, by quantitative assays, including CFT and ELISA (Corbel et al., 2006). Therefore, we used cELISA for the confirmation of RBT results.

Table 2. Univariable analysis of the risk factors for seropositivity to brucellosis in camels $(n=2,250)$ of Oman.

\begin{tabular}{|c|c|c|c|c|c|c|}
\hline Variable & Category & Pos./Tested & $\begin{array}{c}\text { Prevalence } \\
(95 \% \text { CI })\end{array}$ & $p$ value & OR $(95 \%$ CI $)$ & $p$ value \\
\hline \multicolumn{7}{|c|}{ Individual level } \\
\hline \multirow{2}{*}{ Age groups } & $>4 \mathrm{yr}$ & $08 / 1569$ & $0.5(0.2-1)$ & 0.208 & $3.51(0.44-28.09)$ & $\chi^{2}=1.397$ \\
\hline & $\leq 4 \mathrm{yr}$ & $01 / 684$ & $0.2(0-0.8)$ & & 1 & $p=0.237$ \\
\hline \multirow{3}{*}{ Breed } & Local & $9 / 2226$ & $0.4(0.2-0.8)$ & & - & - \\
\hline & Imported & $0 / 18$ & $0(0-18.5)$ & & - & \\
\hline & Cross & $0 / 6$ & $0(0-45.9)$ & & - & \\
\hline \multirow{2}{*}{ Sex } & Male & $0 / 252$ & $0(0-1.5)$ & & - & - \\
\hline & Female & 9/1998 & $0.5(0.2-0.9)$ & & - & \\
\hline \multicolumn{7}{|c|}{ Herd level } \\
\hline \multirow{3}{*}{ Location } & South (Dhofar) & $6 / 162$ & $3.7(1.4-7.9)$ & 0.004 & $7.46(1.49,37.37)$ & $\chi^{2}=5.95$ \\
\hline & & & & & & $p=0.014$ \\
\hline & North (Rest of Oman) & $2 / 390$ & $0.5(0.1-1.8)$ & & 1.0 & - \\
\hline \multirow{2}{*}{ Herd Size } & $>15$ camels & $6 / 233$ & $2.6(1-5.5)$ & 0.038 & $4.19(0.84-20.95)$ & $\chi^{2}=3.044$ \\
\hline & $\leq 15$ camels & $2 / 319$ & $0.6(0.1-2.2)$ & & 1.0 & $p=0.081$ \\
\hline \multirow{2}{*}{ Camel kept with } & Camels only & $7 / 378$ & $1.9(0.7-3.8)$ & 0.244 & $3.26(0.39-26.74)$ & $\chi^{2}=1.216$ \\
\hline & with ruminants & $1 / 174$ & $0.6(0-3.2)$ & & 1.0 & $p=0.270$ \\
\hline \multirow{2}{*}{ Managed } & Separately & $5 / 314$ & $1.6(0.5-3.7)$ & 0.747 & $1.27(0.30-5.36)$ & $\chi^{2}=0.104$ \\
\hline & Mixed & $3 / 238$ & $1.3(0.3-3.6)$ & & 1.0 & $p=0.747$ \\
\hline \multirow{2}{*}{ Replacement } & Open herds & $2 / 47$ & $4.3(0.5-14.5)$ & 0.093 & $3.70(0.73-18.85)$ & $\chi^{2}=2.47$ \\
\hline & Close herds & $6 / 505$ & $1.2(0.4-2.6)$ & & 1.0 & $p=0.116$ \\
\hline \multirow{2}{*}{ Housing } & Loose & $7 / 301$ & $2.3(0.9-4.7)$ & 0.059 & $5.95(7.27-48.71)$ & $\chi^{2}=2.766$ \\
\hline & Confined & $1 / 251$ & $0.4(0-2.2)$ & & 1.0 & $p=0.096$ \\
\hline \multirow{2}{*}{ Abortion history } & Yes & $4 / 60$ & $6.7(1.8-16.2)$ & $<0.001$ & $8.71(2.12,35.81)$ & $\chi^{2}=9.015$ \\
\hline & No & $4 / 492$ & $0.8(0.2-2.1)$ & & 1 & $p=0.003$ \\
\hline
\end{tabular}


Table 3. Final binary logistic regression model for predicting brucellosis at herd level in camels in Oman.

\begin{tabular}{lllccc}
\hline Category & Exposure variable & Comparison & OR & 95\%CI & $\boldsymbol{p}$ value \\
\hline Location of herd & South Oman & North Oman & 6.39 & $1.01-40.67$ & 0.049 \\
Replacement & Open herds & Close herds & 14.49 & $1.83-114.51$ & 0.011 \\
Abortion history & Yes & No & 8.01 & $1.34-47.77$ & 0.022 \\
\hline
\end{tabular}

In the present study, $1.5 \%$ of herds had seropositive animals. Few studies have reported herd-level prevalence in camels (Radwan et al., 1992; Omer et al., 2000; Megersa et al., 2005; Al-Majali et al., 2008; Mohammed et al., 2011); however, the majority of these were not truly representative of the population and targeted specific high-risk components of the population, and hence reported higher values $(10.2 \%-$ $54.2 \%)$. A low herd-level seroprevalence $(<2 \%)$ was observed in this study as compared to previous estimates (3.5\%) in Oman (Ismaily et al., 1988).

Since the sampling plan was constituted to detect at least a single animal positive with the expected prevalence to be $50 \%$, a low-level individual seroprevalence $(0.4 \%)$ was recorded during the study. Individual camel seroprevalence ranging from $1.6 \%$ to $12.1 \%$ have been reported in other studies (Radwan et al., 1992; Kudi et al., 1997; Abou-Eisha, 2000; Omer et al., 2000; Megersa et al., 2005; Al-Majali et al., 2008; Dawood, 2008; Balcha and Fentie, 2011; Mohammed et al., 2011). Low-level individual prevalence ranging from $1.4 \%$ to $2.0 \%$ was reported by the studies from Saudi Arabia, Iran, Abu Dhabi, Egypt, Ethiopia, and Somalia (Baumann and Zessin, 1992; Afzal and Sakkir, 1994; Khadjeh et al., 1999; Abou-Eisha, 2000; Megersa et al., 2005; Mohammed et al., 2011). However, some studies have recorded higher level of overall prevalence, including 7.3\% in Egypt (El-Boshy et al., 2009), 19.4\% in Jordan (Dawood, 2008), 30.5\% in Sudan (Omer et al., 2007), 4.2\% in Ethiopia (Teshome et al., 2003), $3.8 \%$ in Iraq (Jawad, 1984), $7.5 \%$ in Nigeria (Kudi et al., 1997), and 8\% in Pakistan (Straten et al., 1997). The differences in the prevalence reported between the countries are likely to be associated with different environmental and management conditions, the type of study conducted, and the diagnostic test used.

Camels in Dhofar (South of Oman) governorate were more likely to be seropositive (3.7\%, OR: 7.46$)$ than camels from other governorates. This finding highlighted the endemic nature of brucellosis in Dhofar as reported by others (Ismaily et al., 1988; Mehta and El-Mauly, 1990). Approximately, 45\% of camel population in Oman is in Dhofar, and effective control of brucellosis is essential to maintain the productivity of this population. Multispecies contact, a higher population density of livestock, and communal grazing along with faulty management practices adopted by farmers may have contributed to the establishment and maintenance of brucellosis in this governorate (Kudi et al., 1997; Mohammed et al., 2011).
In the current study, evidence of infection was only detected in females. Other studies have also reported higher seroprevalence in females (Tolosa et al., 2008; Bayemi et al., 2009; Hadush et al., 2013). Because of their usefulness in the production herds, females generally have a longer lifespan than males, and this may have increased exposure to the bacterium (Mekonnen et al., 2010). All seropositive camels were of local breeds. No previous studies have reported significant differences between breeds for brucellosis and it is likely that management and husbandry factors are more important than breed in determining the probability of a camel being infected with Brucella (Radwan et al., 1992; 1995).

In our study, the seroprevalence increased with the age of camels. Studies conducted elsewhere have also reported a higher prevalence in adults as compared to younger camels (Megersa et al., 2005; Dawood, 2008; Balcha and Fentie, 2011). The growth and multiplication of Brucella are enhanced by age and sexual maturity and is dependent on the increasing level of sex hormones and erythritol (Poester et al., 2013). Additionally, with age, animals are more likely to be exposed to the organism (Dhand et al., 2005).

In the present study, herds containing more than 15 heads of camels were found more likely (OR 4.19) to contain seropositive animals than smaller ( $\leq 15$ heads) herds. Similar observations were reported by others (Abbas and Agab, 2002; Al-Majali et al., 2008; Balcha and Fentie, 2011; Mohammed et al., 2011; Hadush et al., 2013). Larger herd size increases the opportunity for contact within infected animals, mainly if abortions have occurred (Abbas and Agab, 2002).

We found that camels kept (OR 1.9) and managed (OR 1.6) separately were more likely to test seropositive. Inter-species transmission of disease is a welldocumented phenomenon (Erdenebaatar et al., 2004; Dawood, 2008) and our findings differ with that of Musa and Shigid (2001) and Mohammed et al. (2011), who reported a higher level of seropositivity in camels raised along with cattle. Moreover, results of several studies have documented that camels kept with small ruminants are also more susceptible to get the infection (Ismaily et al., 1988; Radwan et al., 1992; Abou-Eisha, 2000; AlMajali et al., 2008). The difference recorded here could be related to the variations in the herd structure in Oman as compared to the studies conducted elsewhere.

In the present investigation, we found a statistically significant association $(<0.001)$ between seropositivity and herds with a history of abortion. Association 
between Brucella infection and abortion in camels has been described in other studies (Musa and Shigid, 2001; Mohammed et al., 2011) and is a well-recognised sign in most of Brucella infections.

We found that herds with an open herd replacement system (OR 3.70) and loose camels (OR 5.95) were more likely to test seropositive. The selection of breeding stock, introduction of new animals without prior testing, and lack of quarantine might have resulted in the higher prevalence of brucellosis in these herds. Moreover, transhumance is much more pronounced in the pastoral areas of Oman, especially in Dhofar, where the herds of camel graze with other ruminants at common pasture, consequently facilitating the spread of the organism due to increased exposure. Similar was reported in Nigeria (Kudi et al., 1997).

The present study documented that camel brucellosis is endemic, especially in Dhofar governorate of the Sultanate of Oman, albeit, at a very low level. Moreover, due to the limited number of positive samples and a wide confidence interval observed during the logistic regression analysis, the results of risk factor analysis should be interpreted with caution. This low-level seropositivity offers the promise of its control through a test-and-slaughter strategy. However, in case of prized racing camels (sometimes worth million dollars per head), adoption of this policy may not be feasible until a test based upon direct detection of the pathogen is used to confirm the disease. The inclusion of camel in the ongoing vaccination program with Rev. I vaccine in Dhofar warrants execution of carefully planned trials, as Rev. I organism (Brucella melitensis) is known to be excreted in the milk and camel herders often prefer to drink raw (unpasteurized) camel milk. Owing to the uncontrolled movement of animals, the risk of spread of brucellosis in disease-free governorates/regions (North of Oman) cannot be overlooked.

\section{Acknowledgments}

The study was funded by the Agricultural and Fisheries Development Fund (AFDF) of Ministry of Agriculture and Fisheries, Oman.

\section{Conflict of interest}

The authors declare that they have no conflict of interest.

\section{References}

Abbas, B. and Agab, H. 2002. A review of camel brucellosis. Prev. Vet. Med. 55, 47-56.

Abou-Eisha, A.M. 2000. Brucellosis in camels and its relation to public health. Assiut Vet. Med. J. 44, 54-64.

Afzal, M. and Sakkir, M. 1994. Survey of antibodies against various infectious disease agents in racing camels in Abu Dhabi, United Arab Emirates Rev. Sci. Tech. Off. Int. Epiz. 3, 787-792.

Al-Majali, A.M., Al-Qudah, K.M., Al-Tarazi, Y.H. and Al-Rawashdeh, O.F. 2008. Risk factors associated with camel brucellosis in Jordan. Trop. Anim. Health Prod. 40, 193-200.

Balcha, T. and Fentie, T. 2011. Seroprevalence of camel brucellosis in Pastoral areas of Afar, Somali and Oromia Regions, Ethiopia. Bull. Anim. Heal. Prod. Africa 59, 441-448.

Baumann, M.P.O. and Zessin, K.H. 1992. Productivity and health of camels (Camelus dromedarius) in Somalia: associations with trypanosomosis and brucellosis. Trop. Anim. Health Prod. 24, 145-156.

Bayemi, P.H., Webb, E.C., Nsongka, M.V., Unger, H. and Njakoi, H. 2009. Prevalence of Brucella abortus antibodies in serum of Holstein cattle in Cameroon. Trop. Anim. Health Prod. 41, 141-144.

Benkirane, A., El Idrissi, A.H., Doumbia, A. and de Balogh, K. 2014. Innocuity and immune response to Brucella melitensis Rev.1 vaccine in camels (Camelus dromedarius). Open Vet. J. 4, 96-102.

Brown, C., Garin-Bastuji, B., Ziay, G., Hayajneh, W., Al-Fuqaha, S., Hemida, H., Otify, Y., Hailat, I., Alkhlouf, S. and Hailat, N. 2014. Improving the diagnostic capacities of Brucellosis, enhancing the vaccination and control strategies in the Middle East and North Africa. Pak. Vet. J. 34, 263-264.

Cameron, A. 1999. Survey toolbox for livestcok diseases: a practical manual and software package for active surveillance in developing countries. Australian Center for Internationl Agricultural Research, Australia.

Corbel, M.J., Elberg, S.S. and Cosivi, O. 2006. Brucellosis in humans and animals. World Health Organization, Geneva, Switzerland.

Dawood, H.A. 2008. Brucellosis in Camels (Camelus dromedorius) in the south province of Jordan. Am. J. Agric. Biol. Sci. 3, 623-626.

Dhand, N.K., Gumber, S., Singh, B.B., Aradhana, Bali, M.S., Kumar, H., Sharma, D.R., Singh, J. and Sandhu, K.S. 2005. A study on the epidemiology of brucellosis in Punjab (India) using Survey Toolbox. Rev. Sci. Tech. Off. Int. Epiz. 24, 879-885.

El-Amin, E.O., George, L., Kutty, N.K., Choithramani, R.S., Jhaveri, V.P., Salil, P. and Bedair, S.M. 2001. Brucellosis in children of Dhofar Region, Oman. Saudi Med. J. 22, 610-615.

El-Boshy, M., Abbas, H., El-Khodery, S. and Osman, S. 2009. Cytokine response and clinicopathological findings in Brucella infected camels (Camelus dromedarius). Vet. Med. 54, 25-32.

Erdenebaatar, J., Bayarsaikhan, B., Yondondorj, A., Watarai, M., Shirahata, T., Jargalsaikhan, E., Kawamoto, K. and Makino, S. 2004. Epidemiological and serological survey of brucellosis in Mongolia by ELISA using sarcosine extracts. Microbiol. Immunol. 48, 571-577.

Gwida, M., El-Gohary, A., Melzer, F., Khan, I., Rösler, U. and Neubauer, H. 2012. Brucellosis in camels. Res. Vet. Sci. 92, 351-355. 
Hadush, A., Pal, M., Kassa, T. and Zeru, F. 2013. Seroepidemiology of camel brucellosis in the Afar region of Northeast Ethiopia. J. Vet. Med. Anim. Heal. 5, 269-275.

Idris, M.A., Maiwald, M., el-Mauly, K.N. and Ruppel, A. 1993. Human brucellosis in Dhofar, Sultanate of Oman. J. Trop. Med. Hyg. 96, 46-50.

Ismaily, S.I., Harby, H.A. and Nicoletti, P. 1988. Prevalence of Brucella antibodies in four animal species in the Sultanate of Oman. Trop. Anim. Health Prod. 20, 269-270.

Jawad, A.H. 1984. Brucellosis in camels in Iraq. Bull. End. Dis. 24, 45-50.

Khadjeh, G., Zowghi, E. and Zarif-fard, M.R. 1999. Incidence of brucellosis in one-humped camels of Boushehr, Iran. Arch. Razi. Ins. 50, 83-86.

Kudi, A.C., Kalla, D.J.U., Kudi, M.C. and Kapio, G.I. 1997. Brucellosis in camels. J. Arid. Environ. 37, 413-417.

MAF (Ministry of Agriculture and Fisheries). 2003. Annual report, Brucella diagnostic unit. Ministry of Agriculture and Fisheries, Oman.

Megersa, B., Molla, B. and Yigezu, L. 2005. Seroprevalence of brucellosis in camels (Camelus dromedarius) in Borena lowland, Southern Ethiopia. Bull. Anim. Heal. Prod. Africa 53, 252257.

Mehta, F.R. and El-Mauly, K.N. 1990. Is brucellosis a public health problem in Oman? Med. Newsl. Oman 6, 11-14.

Mekonnen, H., Shewit, K. and Moses, K. 2010. Serological survey of bovine brucellosis in barka and arado breeds (Bos indicus) of western Tigray, Ethiopia. Prev. Vet. Med. 94, 28-35.

Mohammed, O., Megersa, B., Abebe, R., Abera, M., Regassa, A., Abdrehman, Y. and Mekuria, S. 2011. Seroprevalence of Brucellosis in camels in and around dire Dawa City, Eastern Ethiopia. J. Anim. Vet. Adv. 10, 1177-1183.

Musa, M.T. and Shigid, M.T.A. 2001. Brucellosis in camels in intensive animal breeding areas of Sudan. Implications in abortion and early-life infections. J. Trop. Livestock Sci. 54, 11-15.

Nicoletti, P. 2002. A short history of brucellosis. Vet. Microbiol. 90, 5-9.

Omer, M.K., Skjerve, E., Holstad, G., Woldehiwet, Z. and Macmillan, A.P. 2000. Prevalence of antibodies to Brucella spp. in cattle, sheep, goats, horses and camels in the State of Eritrea; influence of husbandry systems. Epidemiol. Infect. 125, 447-453.

Omer, M.M., Abdelaziz, A.A., Abusalab, M.A.S. and Ahmed, A.M. 2007. Survey of brucellosis among sheep. goats, camel and cattle in Kassala Area, Eastern Sudan. J. Anim. Vet. Adv. 6, 635-637.

Perrett, L.L., McGiven, J.A., Brew, S.D. and Stack, J.A. 2010. Evaluation of competitive ELISA for detection of antibodies to Brucella infection in domestic animals. Croat. Med. J. 51, 314-319.

Poester, F.P., Samartino, L.E. and Santos, R.L. 2013. Pathogenesis and pathobiology of brucellosis in livestock. Rev. Sci. Tech. 32, 105-115.

Radwan, A.I., Bekairi, S.I., Mukayel, A.A., Al-Bokmy, A.M., Prasad, P.V., Azar, F.N. and Coloyan, E.R. 1995. Control of Brucella melitensis infection in a large camel herd in Saudi Arabia using antibiotherapy and vaccination with Rev. 1 vaccine. Rev. Sci. Tech. 14, 719-732.

Radwan, A.I., Bekairi, S.I. and Prasad, P.V. 1992. Serological and bacteriological study of brucellosis in camels in central Saudi Arabia. Rev. Sci. Tech. $11,837-844$.

Rollefson, K. 2000. The came and human society. In: Selected Yopics on Camelids. Ed., Ghalot, T.K. Camelid Publishers, Bikaner, India, pp: 1-17.

Scrimgeour, E.M., Mehta, F.R. and Suleiman, A.J. 1999. Infectious and tropical diseases in Oman: a review. Am. J. Trop. Med. Hyg. 61, 920-925.

Seleem, M.N., Boyle, S.M. and Sriranganathan, N. 2010. Brucellosis: a re-emerging zoonosis. Vet. Microbiol. 140(3-4), 392-398.

Sprague, L.D., Al-Dahouk, S. and Neubauer, H. 2012. A review on camel brucellosis: a zoonosis sustained by ignorance and indifference. Pathog. Glob. Health 106, 144-149.

Straten, V.M., Bercovich, Z. and Rahman, U.Z. 1997. The diagnosis of brucellosis in female camels (Camelus dromedaries) using the milk ring test and milk ELISA: a pilot study. J. Camel Pract. Res. 4, $165-168$.

Teshome, H., Molla, B. and Tibbo, M. 2003. A seroprevalence study of camel brucellosis in three camel-rearing regions of Ethiopia. Trop. Anim. Health Prod. 35, 381-390.

Thrusfield, M. 2007. Veterinary epidemiology. 3rd Edn., Blackwell Science Ltd., Oxford, UK.

Tibary, A., Fite, C., Anouassi, A. and Sghiri, A. 2006. Infectious causes of reproductive loss in camelids. Theriogenology 66, 633-647.

Tolosa, T., Regassa, F. and Belihu, K. 2008. Seroprevalence study of bovine brucellosis in extensive management system in selected sites of Jimma Zone, Western Ethiopia. Bull. Anim. Health Prod. Africa. 56, 25-37.

Urdaz-Rodríguez, J.H., Fosgate, G.T., Alleman, A.R., Rae, D.O., Donovan, G.A. and Melendez, P. 2009. Seroprevalence estimation and management factors associated with high herd seropositivity for Anaplasma marginale in commercial dairy farms of Puerto Rico. Trop. Anim. Health Prod. 41, 14391448. 